\title{
Nurses' knowledge on pressure injury prevention: a systematic review and meta-analysis based on the Pressure Ulcer Knowledge Assessment Tool
}

This article was published in the following Dove Press journal:

Clinical, Cosmetic and Investigational Dermatology

\author{
Sahar Dalvand' \\ Abbas Ebadi² \\ Reza Ghanei Gheshlagh ${ }^{3,4}$ \\ 'Department of Epidemiology \\ and Biostatistics, School of Public \\ Health, Tehran University of Medical \\ Sciences, Tehran, Iran; ${ }^{2}$ Behavioral \\ Sciences Research Center, Life Style \\ Institute, Nursing Faculty, Baqiyatallah \\ University of Medical Sciences, Tehran, \\ Iran; ${ }^{3}$ Department of Nursing, School \\ of Nursing and Midwifery, Kurdistan \\ University of Medical Sciences, \\ Sanandaj, Iran; ${ }^{4}$ Clinical Care Research \\ Center, Kurdistan University of \\ Medical Sciences, Sanandaj, Iran
}

Correspondence: Reza Ghanei Gheshlagh Department of Nursing, School of Nursing and Midwifery, Kurdistan University of Medical Sciences, Pasdaran Street, 66177-13446 Sanandaj, Kurdistan, Iran

Email rezaghanei30@yahoo.com
Introduction: Inadequate knowledge on pressure injury (PI) can have a detrimental effect on preventive care strategies. The aim of this study was to assess the overall knowledge of nurses on PI prevention based on their scores on the Pressure Ulcer Knowledge Assessment Tool (PUKAT) and its subscales in different settings.

Methods: In this systematic review and meta-analysis, databases including Web of Science, Science Direct, Google Scholar, PubMed, and Scopus were searched, using the following keywords: Pressure Ulcer, Pressure injury, Bedsore, Pressure Sore, Decubitus Ulcer, knowledge, and their possible combinations. Based on heterogeneity between the studies, the data were analyzed using a random effects model. All of the analyses were performed using STATA v.12 software.

Results: In all three groups (nurses, assistant nurses, and nursing students), the lowest knowledge scores were for prevention measures to reduce the amount of pressure/shear. Nurses' knowledge (55.4\%, 95\% CI: 42.4-68.4) was higher than that of nursing students (52.7\%, 95\% CI: 3-49.56) and assistant nurses $(42.2 \%, 95 \%$ CI: $16.4-68)$.

Conclusion: The overall knowledge of nurses on PI prevention was lower than the recommended level (60\%). Regular training courses and review of PI prevention guidelines can be useful in updating the knowledge of nurses, especially assistant nurses and nursing students on PI prevention.

Keywords: pressure injury, knowledge on pressure injury prevention, nurse

\section{Introduction}

Pressure injury (PI) is a painful, costly, but potentially preventable problem that is common in older people and patients with limited mobility. ${ }^{1}$ The cost of the treatment of PI is 2.5 times than its prevention. ${ }^{2}$ PI increases the length of stay in the hospital from 4 to 30 days, decreases quality of life, and increases pain, morbidity, and mortality. ${ }^{3-5}$ Limited use of knowledge is a common problem in clinical practice. Nurses are not completely aware of up-to-date care protocols and may not have enough knowledge on the current evidence-based practices. Sometimes, nurses' activities are not based on knowledge, but rather on intuition, experience, or habit. ${ }^{6}$

Control and prevention of PI requires interdisciplinary collaboration. In order to keep the integrity of patients' skin and prevent the complications of PI, nurses need to receive support and advice from other health professionals. ${ }^{7}$ Different prevalence rates have been reported for PI in different hospital wards. Patients with spinal cord injury, older adults, and especially patients in intensive care units (ICUs) are at a higher risk of developing PI. ${ }^{8}$ 
In the Vanderwee et al's study, only $10 \%$ of the patients at risk of developing PI received adequate preventive care. ${ }^{9}$ Prevention of PI begins by identifying high-risk individuals, systematical examination of skin, using bed and chair support surfaces, changing posture, mobility, and nutritional support. ${ }^{10}$ Low knowledge on PI prevention negatively affects preventive care strategies. ${ }^{11}$ The review of literature suggests that nurses' knowledge on PI prevention is limited and that this lack of knowledge can negatively influence their performance. ${ }^{12}$ There are various tools for evaluating nurses' knowledge on PI prevention that often lack adequate validation, so their results cannot be generalized. ${ }^{13-16}$ The Pressure Ulcer Knowledge Assessment Tool (PUKAT) is a 26-item questionnaire, designed by Beeckman et al to assess nurses' knowledge on pressure injury in six areas of etiology and development (six items), classification and observation (five items), risk assessment (two items), nutrition (one item), reduction in the amount of pressure/shear (seven items), and reduction in the duration of pressure/shear (five items). A score of 16 and higher (out of 26) indicates acceptable level of knowledge and proficiency on PI (60\% of the total score). ${ }^{17}$ The PUKAT has been used in different countries, including Australia, Mexico, China, Italy, Sweden, Ireland, and Belgium, to assess nurses' knowledge on PI prevention. ${ }^{11,18-24}$

PI is an index of nursing care quality, and management of PI is one of the main nursing tasks, which is influenced by nurses' knowledge on this issue. Different studies have reported different results about nurses' knowledge on PI prevention. The results indicated that nurses' level of knowledge on PI prevention ranged from $28 \%$ to $74 \%$. Considering the importance of improving nurses' knowledge on PI prevention, we should first have an insight on their current level of knowledge; this systematic review and meta-analysis was conducted with the aim of evaluating nurses' overall knowledge on PI prevention.

\section{Methods}

\section{Search strategy}

Nurses' knowledge on PI prevention was evaluated based on their scores on the PUKAT, reported in articles conducted from 2010 to March 2018. ${ }^{17}$ The year 2010 was selected because the PUKAT was published in that year, and ever since it has been cited in various research studies. In terms of language, the articles published in English and Spanish were included in the analysis. The search was conducted in Web of Science, Science Direct, Google Scholar, PubMed, and Scopus using the following keywords: Pressure Injury, Pressure Ulcer, Bedsore, Pressure Sore, Decubitus Ulcer, and Knowledge, and their possible combinations. The reference lists of the articles were also reviewed to improve the coverage.

\section{Selection of studies and data extraction}

First, all the articles that had used the keywords in their titles were selected based on inclusion and exclusion criteria. The inclusion criteria were the use of the PUKAT for measuring nurses' knowledge on PI prevention and reporting the required data. Lack of access to the article's full text and use of other tools to gather data were the exclusion criteria. Using the abovementioned criteria, the titles and abstracts of the articles were independently reviewed by two researchers, and the related materials were extracted. In the next step, the full texts of the articles providing useful information were analyzed.

The methodological quality of the articles was analyzed using the Strengthening the Reporting of Observational Studies in Epidemiology (STROBE). This checklist contains 22 items assessing six different sections of research articles, including title and abstract, introduction, method, results, discussion, and sponsorship. ${ }^{25}$ Disagreements between the two researchers were resolved by the correspondent author who was experienced in meta-analysis. The data from the selected articles were recorded in an Excel chart, including the name of the first author, year of publication, country of study, total sample size, target group (nurses, assistant nurses, and nursing students), total scores on the PUKAT, and scores on the six dimensions of the instrument.

\section{Statistical analysis}

Because in the selected studies, total scores on the PUKAT and scores on its six dimensions were provided as percentages, the scores were estimated using the binomial distribution. The variance of each study was calculated using the binomial distribution formula. A weighted mean was used to combine the percentages of the scores in each study, so that each study was weighted in proportion to its variance. Because of the percentage difference in total PI prevention knowledge scores and dimension scores between different studies, and due to the significance of heterogeneity indices, the random effects model was used to combine the studies and estimate the percentage of total and dimension scores. The $I^{2}$ index and Cochran's Q test were used to examine the heterogeneity between the studies ( $I^{2}$ statistics below $25 \%$ indicated low heterogeneity, between $25 \%$ and $50 \%$ moderate heterogeneity, and over $75 \%$ high heterogeneity). For the Cochran's Q test, the $P$-value was set at $<0.1$. The forest plot 
was used for a comprehensive demonstration of the selected studies in terms of effect size and 95\% CI. The selected studies were classified by continents of origin (Europe, Asia, Australia, and America) and target groups (nurses, assistant nurses, and nursing students). In addition, the percentage of overall knowledge on PI prevention and knowledge on the six dimensions of the PUKAT were calculated using the subgroup analysis and the random effects model. The relationship between year of publication and sample size with the percentage of total knowledge on PI prevention was also evaluated using a meta-analysis. Finally, the funnel plot based on the Egger's regression test was used to examine the role of each study in the final result of sensitivity analysis and to investigate the effect of small studies and potential publication error. All analyses were performed using the STATA v.12 software.

\section{Results}

In this systematic review and meta-analysis, all the studies on nurses' knowledge on the prevention of PI were reviewed based on the PRISMA statement. In the initial search, 692 studies were identified, of which 684 were excluded based on the inclusion and exclusion criteria (Figure 1).

Finally, eight studies with 11 groups and a total sample size of 4,766 were analyzed. In terms of methodological quality, four studies had moderate quality ${ }^{19-21,23}$ and four had excellent quality. ${ }^{11,18,22}$ Also, four studies were from Europe (Sweden, Ireland, Belgium, and Italy), ${ }^{11,22-24}$ two studies from Asia (China and Turkey), ${ }^{20,21}$ one from Australia, ${ }^{18}$ and one from Mexico. ${ }^{19}$ The studies had been conducted between 2012 and 2018. The highest and the lowest knowledge on PI prevention scores were in the Lui et al's study in China (among nurses) and Demarré et al's study in Belgium (among assistant nurses), respectively. ${ }^{21,24}$ More details are reported in Table 1.

Nurses' total score on PI prevention is presented in Figure 2.The percentage of total PI prevention knowledge was 53.1\% (95\% CI: 47.5-58.8), which was acceptable, but not desirable (Figure 2).

The percentages of PI prevention scores based on the dimensions of the PUKAT are presented in Figure 3. The

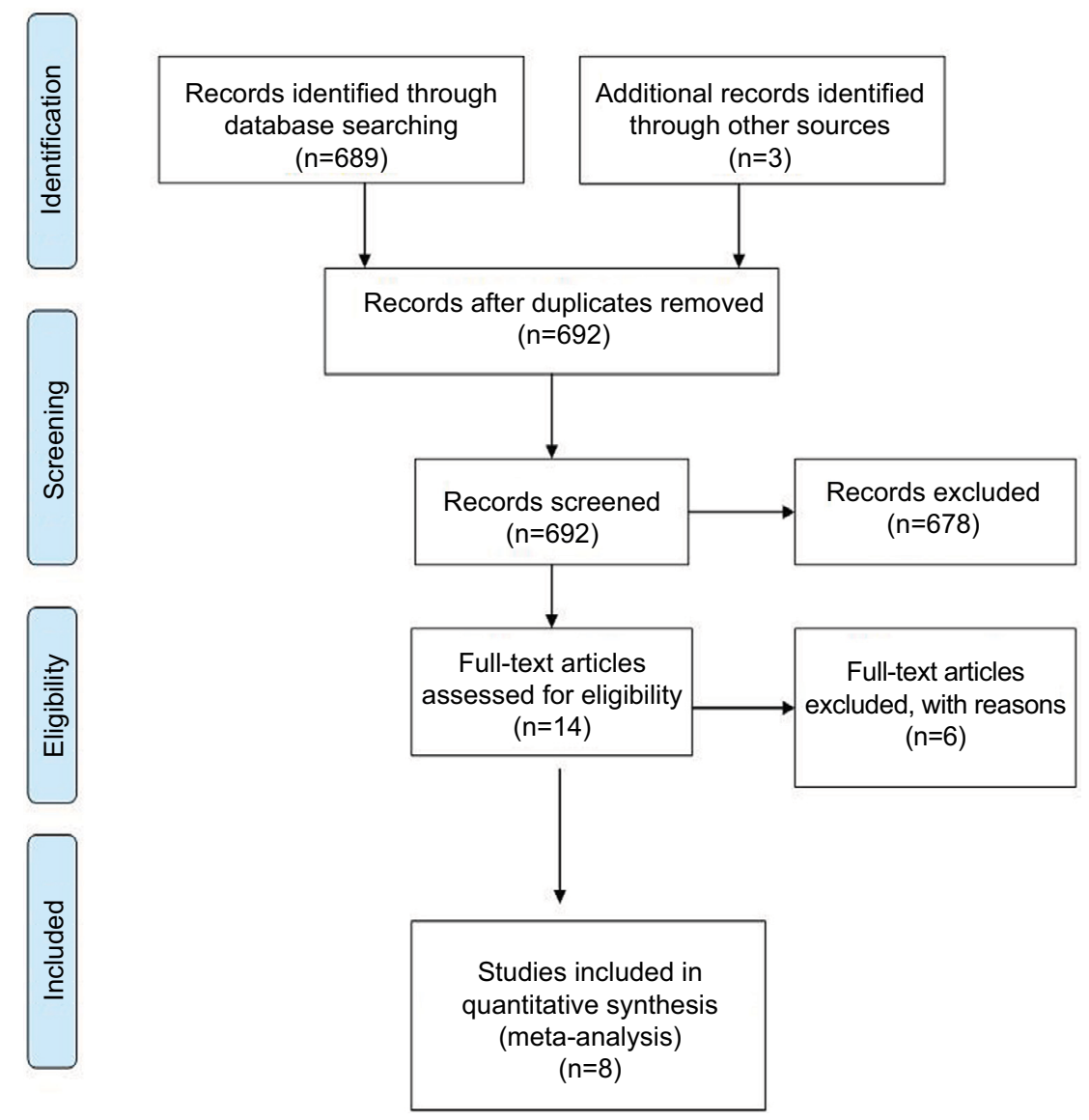

Figure I Screening flowchart showing the selection of qualified articles according to the PRISMA statement. Abbreviation: PRISMA, Preferred Reporting Items for Systematic Reviews and Meta-Analyses. 
Table I Characteristics of the selected articles

\begin{tabular}{|c|c|c|c|c|c|}
\hline Target group & Place & Male (n) & Sample size & Year & Reference \\
\hline Nursing students & Australia & 433 & 2,949 & 2018 & Usher et $\mathrm{al}^{18}$ \\
\hline Nurses & Mexico & 47 & 119 & 2017 & Garza Hernández et al ${ }^{19}$ \\
\hline Nurses & Turkey & Not reported & 150 & 2016 & 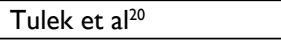 \\
\hline Nurses & China & 7 & 186 & 2016 & Liu et $\mathrm{al}^{21}$ \\
\hline Nursing students & Italy & 191 & 742 & 2015 & Simonetti et al" \\
\hline Nursing students & \multirow[t]{3}{*}{ Sweden } & 8 & 122 & \multirow[t]{3}{*}{2015} & \multirow[t]{3}{*}{ Gunningberg et $\mathrm{al}^{22}$} \\
\hline Nurses & & 8 & 97 & & \\
\hline Nursing assistants & & 13 & 196 & & \\
\hline Nursing students & Ireland & Not reported & 60 & 2013 & Cullen Gill et $\mathrm{al}^{23}$ \\
\hline Nurses & \multirow[t]{2}{*}{ Belgium } & 6 & 54 & \multirow[t]{2}{*}{2012} & \multirow[t]{2}{*}{ Demarré et $\mathrm{al}^{24}$} \\
\hline Nursing assistants & & 4 & 91 & & \\
\hline
\end{tabular}

Study

ID
$\%$

Proportion $(95 \% \mathrm{Cl})$ Weight

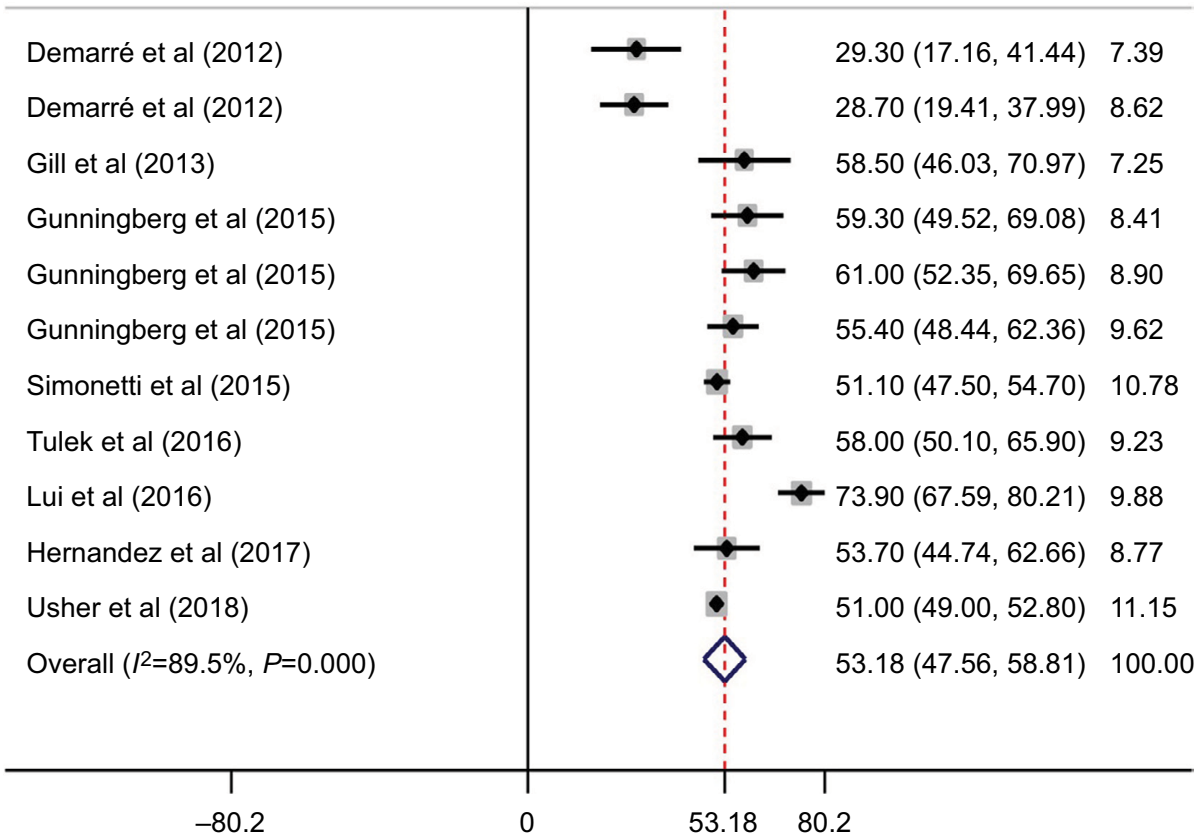

Figure 2 Forest plot showing the percentages of total scores on PI prevention based on the PUKAT.

Note: Weights are from random effects analysis.

Abbreviations: PI, pressure injury; PUKAT, Pressure Ulcer Knowledge Assessment Tool.

highest and the lowest percentages of dimension scores were for nutrition (D4) $(68 \%, 95 \% \mathrm{CI}$ : 49-87) and preventive measures to reduce the amount of pressure/shear (D5) (44.6\%, 95\% CI: 39.6-49.7), respectively (Figure 3).

The percentage of nurses' total knowledge on PI prevention $(55.4 \%, 95 \%$ CI: $42.3-68.4)$ was higher than that of nursing students $(52.7 \%, 95 \%$ CI: $49.3-56)$ and assistant nurses (42.2\%, 95\% CI: 16-68.4). The level of knowledge by groups revealed that for all the three groups of nurses (49.5\%, 95\% CI: 41.2-57.9), assistant nurses (35.6\%, 95\% CI: 5/5-55.9), and nursing students (42.5\%, 95\% CI: 36.5-48.4), the lowest scores were on preventive measures to reduce the amount of pressure/shear (D5). For nursing students (89.1\%, 95\% CI: 85.5-92.6) and nurses (68.7\%, 95\% CI: $32.9-104.6)$, the highest scores were on nutrition (D4), while for assistant nurses $(62.5 \%, 95 \% \mathrm{CI}$ : 47.6-77.4), the highest scores were on risk assessment (D3) (Table 2).

Results based on continent showed that the highest percentage of PI prevention knowledge based on the six dimensions of the PUKAT was for the studies conducted in Asia. The lowest scores on all dimensions, except on risk management (D3), were for the studies conducted in Europe. The lowest scores on risk management (D3) were for the studies conducted in the other continents (North America and Australia). 


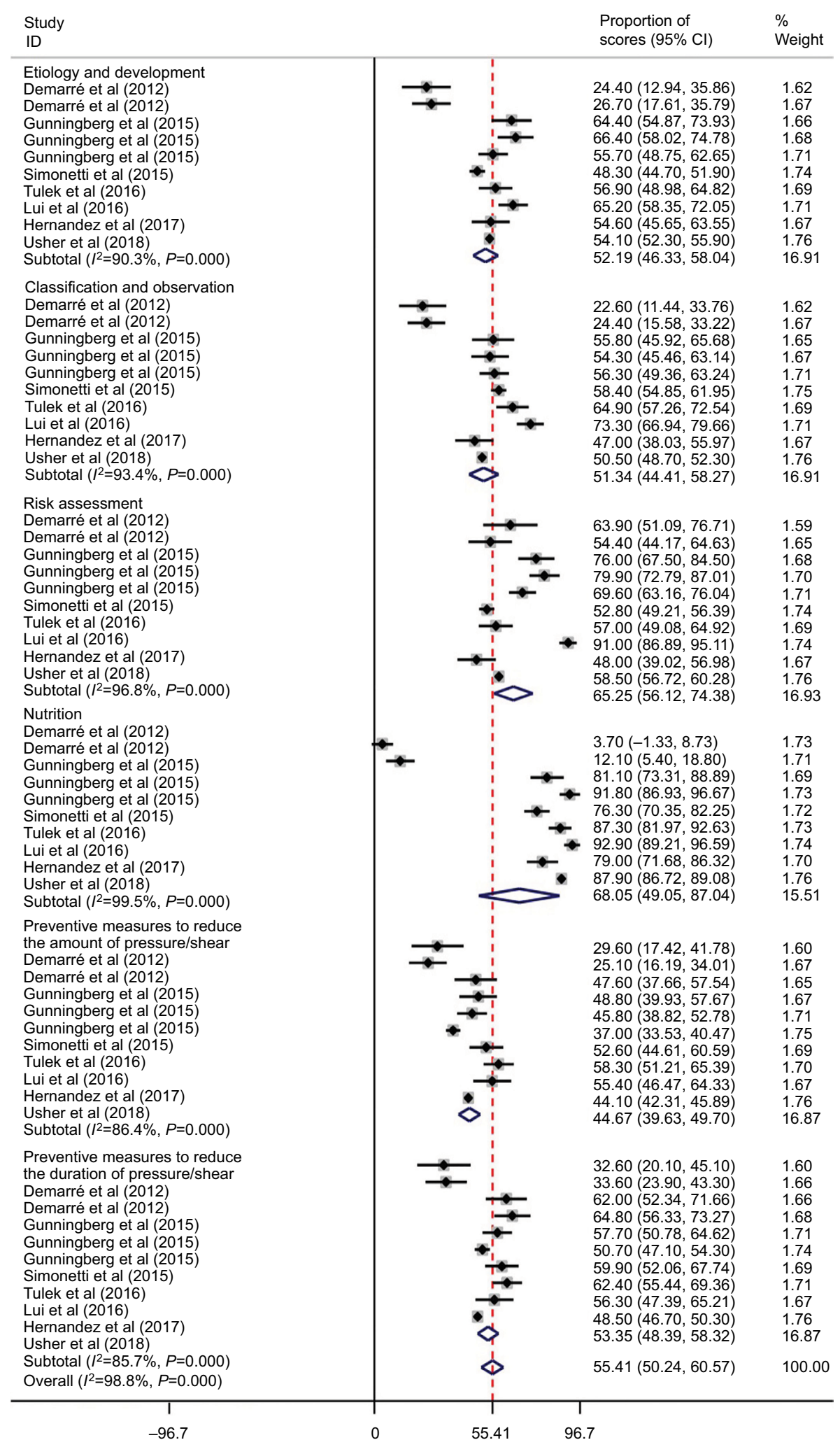

Figure 3 Forest plot showing the percentage of PI prevention scores based on the domains of the PUKAT.

Note: Weights are from random effects analysis.

Abbreviations: PI, pressure injury; PUKAT, Pressure Ulcer Knowledge Assessment Tool.

Sensitivity analysis indicated that none of the studies alone had a significant effect on estimating the percentage of total knowledge. In addition, the publication bias was not significant $(P=689$; Figure 4$)$.
The results of meta-regression analysis showed that there was no relationship between sample size and nurses' total knowledge on PI prevention $(P=0.922)$. Although nurses' knowledge increased by year of publi- 
Table 2 Nursing groups' scores on different dimensions of pressure injury prevention knowledge

\begin{tabular}{|c|c|c|c|c|c|c|c|}
\hline \multirow[t]{2}{*}{ Domain } & \multirow[t]{2}{*}{ Target } & \multirow{2}{*}{$\begin{array}{l}\text { Number } \\
\text { of studies }\end{array}$} & \multirow{2}{*}{$\begin{array}{l}\text { Proportion } \\
\text { of scores (\%) }\end{array}$} & \multirow[t]{2}{*}{$95 \% \mathrm{Cl}$} & \multicolumn{3}{|c|}{ Heterogeneity } \\
\hline & & & & & $12(\%)$ & $\mathbf{Q}$ & $P$-value \\
\hline \multirow[t]{3}{*}{ DI } & Nurses & 5 & 53.5 & $41.3-65.7$ & 89.8 & 39.19 & 0.001 \\
\hline & Nursing assistants & 2 & 41.3 & $12.9-69.7$ & 95.9 & 24.67 & 0.001 \\
\hline & Nursing students & 3 & 55 & $48.4-61.5$ & 88.6 & 17.55 & 0.001 \\
\hline \multirow[t]{3}{*}{ D2 } & Nurses & 5 & 53 & $37.1-68.9$ & 94.3 & 69.89 & 0.001 \\
\hline & Nursing assistants & 2 & 40.4 & $9.2-71.7$ & 96.8 & 31.00 & 0.001 \\
\hline & Nursing students & 3 & 54.2 & $48-60.4$ & 87 & 15.37 & 0.001 \\
\hline \multirow[t]{3}{*}{ D3 } & Nurses & 5 & 67.3 & $49.4-85.6$ & 96.5 & 113.05 & 0.001 \\
\hline & Nursing assistants & 2 & 62.5 & \begin{tabular}{|l|}
$47.6-77.4$ \\
\end{tabular} & 83.5 & 6.07 & 0.014 \\
\hline & Nursing students & 3 & 63 & $53.1-72.9$ & 95.5 & 44.46 & 0.001 \\
\hline \multirow[t]{3}{*}{ D4 } & Nurses & 5 & 68.7 & $32.9-104.6$ & 99.5 & 868.15 & 0.001 \\
\hline & Nursing assistants & 2 & 44.2 & $-18.7-107.1$ & 99.5 & 197.08 & 0.001 \\
\hline & Nursing students & 3 & 89.1 & $85.5-92.6$ & 57.1 & 2.33 & 0.127 \\
\hline \multirow[t]{3}{*}{ D5 } & Nurses & 5 & 49.5 & $41.2-57.9$ & 76.9 & 17.35 & 0.001 \\
\hline & Nursing assistants & 2 & 35.6 & $15.3-55.9$ & 92.2 & 12.86 & 0.001 \\
\hline & Nursing students & 3 & 42.4 & $36.5-48.4$ & 86.2 & 14.49 & 0.001 \\
\hline \multirow[t]{3}{*}{ D6 } & Nurses & 5 & 55.5 & $47-64.1$ & 78.3 & 18.39 & 0.001 \\
\hline & Nursing assistants & 2 & 45.9 & $22.2-69.5$ & 93.6 & $15.7 \mid$ & 0.001 \\
\hline & Nursing students & 3 & 53 & $47-58.9$ & 85.5 & 14.13 & 0.001 \\
\hline
\end{tabular}

Notes: DI: domain I (etiology and development); D2: domain 2 (classification and observation); D3: domain 3 (risk assessment); D4: domain 4 (nutrition); D5: domain 5 (preventive measures to reduce the amount of pressure/shear); and D6: domain 6 (preventive measures to reduce the duration of pressure/shear).

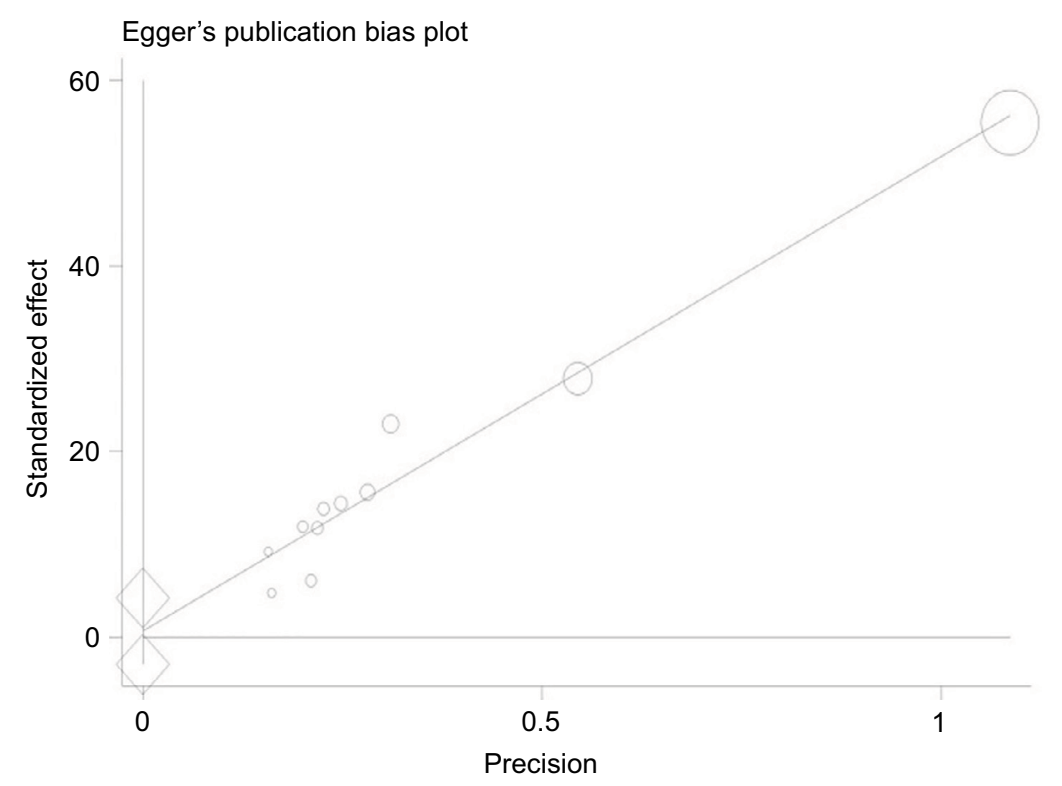

Figure 4 Publication bias.

cation, this upward trend was not statistically significant $(P=0.061)$.

\section{Discussion}

In the present meta-analysis, a total of eight studies with a total sample size of 4,766 were analyzed in order to assess nurses' knowledge on PI prevention. The results indicated that the total score of nurses on PI prevention was lower than the cutoff point of the PUKAT (more than $60 \%$ of the total score). ${ }^{17}$ The lowest score of nurses, assistant nurses, and nursing students was on preventive measures to reduce the amount of pressure/shear. In addition, knowledge on PI prevention was higher for nurses than assistant nurses and nursing students.

The study results indicated that nurses' total knowledge on PI prevention was 53.1\%. This shows that nurses still do 
not have the sufficient level of knowledge on PI prevention. When nurses do not have enough knowledge on PI prevention, patients cannot be hopeful to receive evidence-based practice. The studies conducted in different countries have also shown that nurses do not have enough knowledge on PI prevention. ${ }^{26-28}$ In other words, nurses' limited knowledge on PI prevention is not influenced by geographical regions.

The findings showed that nurses' total knowledge on PI prevention was higher than that of nursing students and assistant nurses. The knowledge score of nursing students was also higher than that of assistant nurses. Factors that may have contributed to this result were nurses' having more clinical experience, more opportunities to visit patients with various levels of pressure ulcer, and receiving training courses in the hospital useful in updating their knowledge on PI prevention. Contrary to our expectation, nursing students' knowledge was lower than that of nurses; this can be attributed to their limited clinical experiences. In the study by Aydin and Karadağ (2010), receiving training and previous experiences with patients was associated with nurses' knowledge on PI prevention. ${ }^{26}$

The highest and the lowest PI prevention knowledge scores were on nutrition and preventive measures to reduce the amount of pressure/shear. In fact, for all the three groups of nurses, assistant nurses, and nursing students, the lowest scores were on preventive measures to reduce the amount of pressure/shear. This dimension includes nurses' knowledge on repositioning, positions for reducing the risk of ulcer, timing of repositioning in patients lying on the viscoelastic foam, disadvantages of water mattresses, and the common location of pressure ulcer. In the study by Hulsenboom et al, less than half of the nurses knew that putting heels on ring-shaped cushions or water-filled gloves could reduce the pressure applied to the heel. ${ }^{29}$ In Schoeps et al's study (2017), less than half of the nurses followed the strategies for PI prevention, such as repositioning. ${ }^{30}$ In a study by Källman and Suserud (2009), pressure relieving was the third commonly used strategy for PI prevention after regular repositioning and the use of pressure reducing mattresses. ${ }^{15}$ The results of this study indicated that between 2012 and 2018, nurses' knowledge on PI prevention remained unchanged. The results of the study by Hulsenboom et al showed an increase in nurses' knowledge on PI prevention between 1991 and 2003. ${ }^{29}$ In a study by Mwebaza et al, one-third of nurses admitted that they did not assess patients' bodies for pressure ulcer. ${ }^{31}$ In the Lawrence et al's study, $93 \%$ of nurses were still unaware that massage was not recommended for the prevention of PI. ${ }^{5} \mathrm{PI}$ is a multifactorial problem that, despite being preventable in theory, may occur in care set- tings with the highest quality. ${ }^{8}$ Appropriate nursing care is an essential component of PI prevention. Therefore, nurses' level of knowledge on this issue is vital in the prevention of PI in the patients, based on evidence-based practice. ${ }^{20}$

The PUKAT was developed 8 years ago, and ever since it has been used in different studies. One of the strength of the present meta-analysis was that it was the first study assessing and reporting nurses' knowledge on PI prevention based on the PUKAT. By drawing on the findings of this meta-analysis, researchers can easily compare nurses' knowledge on PI prevention with the expected level, and get some insight on the nurses' current level of knowledge on this issue. Among the limitation of the meta-analysis was that some articles had not reported the necessary information, or had used modified versions of the PUKAT (adding some items to the original items); therefore, they could not be used in the analysis. Another limitation was related to the translation of the original scale that had some semantic difference with the original form. Only in psychometric studies, the translated instrument is sent to the developer to be examined and verified in terms of translation, and these studies are not concerned with the quality of translation. Among the eight analyzed articles, only two were psychometric studies that had been conducted in China and Turkey. Among the six studies, five were in English and one in Spanish. Considering that the original questionnaire and the other studies were all in English, the concern of proper translation was only with the Mexican study that was in English. Review of the studies conducted on nurses' knowledge on PI prevention showed that nurses' knowledge on this issue was lower than the expected level. Nurses' limited knowledge on PI prevention can both reduce the quality of nursing care and increase the risk of PI in the patients. Regular training courses and review of PI prevention guidelines can be useful in improving nurses' knowledge, help the application of this knowledge in clinical practice, and ultimately reduce the incidence of PI.

\section{Disclosure}

The authors report no conflicts of interest in this work.

\section{References}

1. Reddy M, Gill SS, Rochon PA. Preventing pressure ulcers: a systematic review. JAMA. 2006;296(8):974-984.

2. Nuru N, Zewdu F, Amsalu S, Mehretie Y. Knowledge and practice of nurses towards prevention of pressure ulcer and associated factors in Gondar University Hospital, Northwest Ethiopia. BMC Nurs. 2015;14(1):34-42.

3. Black J, Girolami S, Woodbury G, et al. Understanding pressure ulcer research and education needs: a comparison of the association for the advancement of wound care pressure ulcer guideline evidence levels and content validity scores. Ostomy Wound Manage. 2011;57(11):22. 
4. Gorecki C, Brown JM, Nelson EA, et al. Impact of pressure ulcers on quality of life in older patients: a systematic review. J Am Geriatr Soc. 2009;57(7):1175-1183.

5. Lawrence P, Fulbrook P, Miles S. A survey of Australian nurses' knowledge of pressure injury/pressure ulcer management. $J$ Wound Ostomy Continence Nurs. 2015;42(5):450-460.

6. Qaddumi J, Khawaldeh A. Pressure ulcer prevention knowledge among Jordanian nurses: a cross- sectional study. BMC Nurs. 2014;13(1):6.

7. Samuriwo R. Pressure ulcer prevention: the role of the multidisciplinary team. Br J Nurs. 2012;21(5):S4-S13.

8. Ghanee R, Gavami H. Bed sores in ICU. J Urmia Nurs Midwifery Fac. 2010;8(2):90-103.

9. Vanderwee K, Clark M, Dealey C, Gunningberg L, Defloor T. Pressure ulcer prevalence in Europe: a pilot study. J Eval Clin Pract. 2007;13(2):227-235.

10. Hommel A, Gunningberg L, Idvall E, Bååth C. Successful factors to prevent pressure ulcers - an interview study. J Clin Nurs. 2017;26(1-2):182-189.

11. Simonetti V, Comparcini D, Flacco ME, di Giovanni P, Cicolini G. Nursing students' knowledge and attitude on pressure ulcer prevention evidence-based guidelines: a multicenter cross-sectional study. Nurse Educ Today. 2015;35(4):573-579.

12. Gunningberg L, Lindholm C, Carlsson M, Sjödén PO. Risk, prevention and treatment of pressure ulcers--nursing staff knowledge and documentation. Scand J Caring Sci. 2001;15(3):257-263.

13. Pieper B, Mattern J. Critical care nurses' knowledge of pressure ulcer prevention, staging and description. Ostomy Wound Manage. 1997;43(28):22-6:30-31.

14. Halfens RJ, Eggink M. Knowledge, beliefs and use of nursing methods in preventing pressure sores in Dutch hospitals. Int J Nurs Stud. 1995;32(1):16-26.

15. Källman U, Suserud BO. Knowledge, attitudes and practice among nursing staff concerning pressure ulcer prevention and treatment--a survey in a Swedish healthcare setting. Scand J Caring Sci. 2009;23(2):334-341.

16. Moore Z, Price P. Nurses' attitudes, behaviours and perceived barriers towards pressure ulcer prevention. J Clin Nurs. 2004;13(8):942-951.

17. Beeckman D, Vanderwee K, Demarré L, Paquay L, van Hecke A, Defloor T. Pressure ulcer prevention: development and psychometric validation of a knowledge assessment instrument. Int J Nurs Stud. 2010;47(4):399-410.

18. Usher K, Woods C, Brown J, et al. Australian nursing students' knowledge and attitudes towards pressure injury prevention: a cross-sectional study. Int J Nurs Stud. 2018;81:14-20.
19. Garza Hernández R, Meléndez Méndez M, Huerta F, et al. Conocimiento, actitud y barreras en enfermeras hacia las medidas de prevención de úlceras por presión. Ciencia y enfermería. 2017;23(3):47-58.

20. Tulek Z, Polat C, Ozkan I, Theofanidis D, Togrol RE. Validity and reliability of the Turkish version of the pressure ulcer prevention knowledge assessment instrument. J Tissue Viability. 2016;25(4):201-208.

21. Liu M, Yuan H-B, Chen W-J, Poon C, Hsu M, Zhang B. Translation, modification and validation of the Chinese version of a knowledge assessment instrument regarding pressure ulcer prevention. Chinese Nursing Research. 2016;3(1):16-23.

22. Gunningberg L, Mårtensson G, Mamhidir AG, Florin J, Muntlin Athlin Å, Bååth C. Pressure ulcer knowledge of registered nurses, assistant nurses and student nurses: a descriptive, comparative multicentre study in Sweden. Int Wound J. 2015;12(4):462-468.

23. Cullen Gill E, Moore Z. An exploration of fourth-year undergraduate nurses' knowledge of and attitude towards pressure ulcer prevention. $J$ Wound Care. 2013;22(11):618-627.

24. Demarré L, Vanderwee K, Defloor T, Verhaeghe S, Schoonhoven L, Beeckman D. Pressure ulcers: knowledge and attitude of nurses and nursing assistants in Belgian nursing homes. J Clin Nurs. 2012;21(9-10):1425-1434.

25. Farrugia MK, Kirsch AJ. Application of the Strengthening the Reporting of Observational Studies in Epidemiology (STROBE) statement to publications on endoscopic treatment for vesicoureteral reflux. J Pediatr Urol. 2017;13(3):320-325.

26. Aydin AK, Karadağ A. Assessment of nurses' knowledge and practice in prevention and management of deep tissue injury and stage I pressure ulcer. J Wound Ostomy Continence Nurs. 2010;37(5):487-494.

27. Iranmanesh S, Rafiei H, Foroogh Ameri G. Critical care nurses' knowledge about pressure ulcer in southeast of Iran. Int Wound J. 2011;8(5):459-464.

28. Uba MN, Alih FI, Kever RT, Lola N. Knowledge, attitude and practice of nurses toward pressure ulcer prevention in University of Maiduguri Teaching Hospital, Borno State, North-Eastern, Nigeria. Int J Nurs Midw. 2015;7(4):54-60.

29. Hulsenboom MA, Bours GJ, Halfens RJ. Knowledge of pressure ulcer prevention: a cross-sectional and comparative study among nurses. BMC Nurs. 2007;6(1):2.

30. Schoeps LN, Tallberg AB, Gunningberg L. Patients' knowledge of and participation in preventing pressure ulcers - an intervention study. Int Wound J. 2017;14(2):344-348.

31. Mwebaza I, Katende G, Groves S, Nankumbi J. Nurses' knowledge, practices, and barriers in care of patients with pressure ulcers in a Ugandan teaching hospital. Nurs Res Pract. 2014;2014(3):1-6.
Clinical, Cosmetic and Investigational Dermatology

\section{Publish your work in this journal}

Clinical, Cosmetic and Investigational Dermatology is an international, peer-reviewed, open access, online journal that focuses on the latest clinical and experimental research in all aspects of skin disease and cosmetic interventions. This journal is included on PubMed. The manuscript management system is completely online

\section{Dovepress}

and includes a very quick and fair peer-review system, which is all easy to use. Visit http://www.dovepress.com/testimonials.php to read real quotes from published authors 